\title{
EDITORIAL
}

\section{Guofang SHEN}

\section{Modern scholarly publishing calls for originality: an announcement for suspension of journal publication}

\author{
(c) Higher Education Press and Springer-Verlag 2009
}

Frontiers of Forestry in China was launched in 2006 to promote rapid communication and exchanges between forestry researchers in China and abroad. Over the past four years, Frontiers of Forestry in China has contributed over 300 quality papers to the global document database. These articles are translated from leading Chinese forestry journals, covering all the areas of forestry with an inclination on forest ecology. They have been focused, in particular, on a few worldwide hot topics, such as global climate change and carbon consumption. SpringerLink data shows an increasing annual article downloads. I believe with this journal the academic research work carried out in Chinese universities have been significantly disseminated.

However, this selection and translation model of journal publishing is not up-to-date with the world trend of scholarly publishing for a lot of reasons including publishing lag and difficulty in getting a smooth copyright transfer. Scholarly publishing, by its nature, requires rapid scientific communication, hence new, original papers are needed rather than translated ones. In that case we have come to decide to cease the publishing of Frontiers of Forestry in China from the year 2010.

In spite of all the difficulties, the journal kept on going for four years with the aid of the editorial board, the publishers, the authors and others. Here, I would give my grateful acknowledgement to the board members who spent time selecting papers from mountains of materials and gave helpful advice. My thanks also go to Higher Education Press, the publisher, which offers financial support as well as quality supervision to the journal, and to Springer-Verlag which provides an international platform for scholarly communication and a broad readership. Gratitude is also given to the authors who are keen to contribute their translations for a scientific exchange. In addition, the editorial stuff from the journal publishing department of Beijing Forestry University who are responsible for the journal editing also deserve respects.

\section{沈国舫}

Guofang SHEN

Editor-in-Chief 